Revue d'histoire de l'Amérique française

REVUE D.HISTOIRE DE L'AMÉRIQUE FRANÇAISE

LANCTOT, Gustave, Montréal sous Maisonneuve 1642-1665.

Librairie Beauchemin, Montréal, 1966. Carte et illustrations, $333 \mathrm{p}$.

\title{
Paul Gay
}

Volume 20, numéro 4, mars 1967

URI : https://id.erudit.org/iderudit/302621ar

DOI : https://doi.org/10.7202/302621ar

Aller au sommaire du numéro

Éditeur(s)

Institut d'histoire de l'Amérique française

ISSN

0035-2357 (imprimé)

1492-1383 (numérique)

Découvrir la revue

Citer ce compte rendu

Gay, P. (1967). Compte rendu de [LANCTOT, Gustave, Montréal sous

Maisonneuve 1642-1665. Librairie Beauchemin, Montréal, 1966. Carte et

illustrations, 333 p.] Revue d'histoire de l'Amérique française, 20(4), 636-638.

https://doi.org/10.7202/302621ar d'utilisation que vous pouvez consulter en ligne.

https://apropos.erudit.org/fr/usagers/politique-dutilisation/ 
LANCTOT, Gustave, Montréal sous Maisonneuve 1642-1665. Librairie Beauchemin, Montréal, 1966. Cartes et illustrations, 333 pages.

$\mathrm{Au}$ moment où le monde entier a les yeux tournés vers Montréal à l'occasion de l'Exposition universelle de 1967, l'historien Gustave Lanctot étudie la naissance et les premières années de Montréal sous l'administration paternelle de son gouverneur, Maisonneuve.

La lecture de cet ouvrage est aisée et passionnante. Revivent les noms prestigieux du passé de la métropole. C'est de France qu'est partie l'idée de Montréal, dans le cœur de Monsieur Olier et de celui que la Providence lui désigne: Jérôme Le Royer de La Dauversière. La sainteté de ces deux personnages, leur amour du Canada, sont les deux piliers sur lesquels va se fonder la colonie naissante. Avec un dévouement inlassable, une intelligence extraordinaire et une faculté d'adaptation rare pour l'époque, de La Dauversière, encouragé par Monsieur Olier, poursuit de loin au Canada une tâche ardue et silencieuse, souriant au milieu des épreuves, ne s'énervant jamais, même quand les attaques viennent d'ennemis autres que les Iroquois. Lanctot se croit en droit d'écrire en parlant de Royer de La Dauversière. "C'est cet homme-là qui fut le véritable fondateur de Montréal."

A côté de lui, d'autres noms dont le souvenir remplit toujours d'émotion le cœur des Canadiens français: Madame de Bullion, qui, de France soutenait de son argent inépuisable la fondation hésitante; Madame de La Peltrie; Marguerite Bourgeoys et la Congrégation Notre-Dame; Jeanne Mance et l'Hôtel-Dieu.

Les amis de Montréal fondent la Société de Notre-Dame de Montréal et lui désignent comme chef Paul de Chomedey, sieur de Maisonneuve. Sous sa direction, la petite société s'organise lentement. Elle a juste quelques centaines de membres qu'elle est déjà en lutte contre les cent Associés tout-puissants et les Jésuites de Québec. La lecture de ces chicanes est pénible. Lanctot a-t-il noirci les Pères de la Compagnie qui donnent l'impression fâcheuse qu'eux seuls sont capables de sauver le monde? Je ne sais pas. Mais à la lecture de l'ouvrage, il apparaît évident que le Saint-Esprit n'avait pas consulté les Jésuites pour inspirer 
M. Olier et de La Dauversière à fonder Montréal. Le plus triste, toujours d'après notre auteur, c'est que les Jésuites ont leur homme bien à eux, Mgr de Laval: ce sont eux qui l'ont fait nommer à l'évêché de Québec, ce sont eux qui le conseillent, surtout le Père Ragueneau, son inséparable. Et les différends s'ajoutent aux différends: lutte de $\mathrm{Mgr}$ de Laval contre l'abbé de Queylus, grand vicaire de Montréal, nommé par l'évêque de Rouen; lutte de Mgr de Laval contre Maisonneuve, à propos d'un terrain vendu à Jeanne Mance par la Société de Montréal. Lanctot va jusqu'à écrire: "Mgr de Laval ne cessa de manifester à l'égard de Montréal, à la suite de ses différends avec l'abbé de Queylus, un esprit d'opposition ouverte, démuni de mesure et d'équité." De telles remarques sont extrêmement douloureuses, surtout à l'égard de Mgr de Laval, que son ardeur apostolique et sa piété ont déjà depuis longtemps canonisé dans l'esprit des Canadiens. Douloureux? Mais si c'est l'histoire, la vraie, l'authentique histoire? Pourquoi les saints ne se tromperaient-ils jamais?

Ainsi, dès le début, alors que leur vie n'est pas même assurée, les Français de Montréal et ceux de Québec ne s'entendent pas. Québec se dresse contre l'autonomie religieuse, politique et économique de Montréal. Maisonneuve tient tête à l'orage, mais sans orgueil ni vantardise. Lanctot s'est bien gardé de décrire le fond de l'âme de cet homme-là ; c'était peut-être impossible. Il n'a vu que l'homme politique. Mais comme les actions extérieures d'un homme sont toujours l'expression de son cœur, on ne peut qu'admirer Maisonneuve, son humilité, sa piété, son esprit de justice, son amour paternel pour toutes les âmes dont il avait la charge, son désintéressement. Celui qu'on gratifie du glorieux titre de fondateur de Ville-Marie y a résidé de 1642 à 1665 et est retourné (exilé) mourir en France, rappelé par le Roi à la demande de Québec.

Gustave Lanctot, s'il ne craint pas les grandes fresques de toute une large époque, triomphe dans les espaces de courtes périodes comme celle qui est étudiée ici. La méthode chronologique qu'il affectionne lui sert merveilleusement pour son tableau des premières années de Montréal. La science ressuscite le passé. On reste rêveur en comparant la métropole de 1967 et sa gigantesque Exposition universelle aux premières maisons d'il y a 300 ans! Où sont les pieux de la palissade de 1641? Là où dansent les millions de dollars actuellement, il n'y avait alors qu'une pauvre petite chapelle, un hôpital minable et quelques maisonnées en planches. Où il y a maintenant plus d'un million 
d'habitants, il n'y avait alors que quelques centaines de Français et de Canadiens, attendant de France l'arrivée des "épouseuses" pour contracter mariage. Où il y a maintenant d'innombrables langues, on n'entendait alors que le doux parler du XVIIe français. Où circulent les luxueuses voitures américaines, il n'y avait alors que des champs que les premiers colons cultivaient en gardant toujours le fusil en bandoulière, par crainte des Iroquois. Et dans ces temps fabuleux, les héros abondaient: Dollard et ses compagnons, Lambert Closse, Charles Le Moyne et tant d'autres. Lanctot accorde à chacun son dû d'histoire: il pense que la meilleure apologétique est de laisser parler les faits. Ainsi, Dollard, que certains ont trop élevé en admiration et que d'autres ont ravalé au point d'en faire un bandit, apparaît tel qu'il fut: un héros qui n'était pas saint, un passionné d'aventure qui, en allant arrêter un convoi de fourrures iroquoises, fut obligé de livrer au Long-Sault un combat imprévu à forces cruellement inégales: une poignée de Français contre 500 Iroquois. Les Français moururent tous; mais les Iroquois s'en retournèrent chez eux et Montréal fut sauvée.

Epoque aux mœurs rudes où le Français de France et le Canadien de lui issu étaient d'une singulière couleur. Ces hommes et ces femmes n'étaient pas des pleutres! Ils commençaient l'histoire d'une nouvelle branche française qui fleurirait au XVIIIe siècle et s'épanouirait dans une véritable civilisation originale. 1760 hélas !... Les Montréalistes - comme on disait jadis - peuvent être fiers de leurs origines. Lanctot, en évoquant ces premières années, ne peut s'empêcher de dire qu'elles constituent "un milieu entre le mysticisme et le miracle". Le catholique qui les revoit en imagination a toutes les raisons du monde pour y distinguer la main de Dieu. Cela, notre auteur ne le dit pas expressément: sans doute parce qu'une telle affirmation déborderait pour lui le cadre de l'histoire, sans doute aussi parce que les faits rapportés suintent par eux-mêmes la Providence. M. Drapeau, successeur de Maisonneuve, à qui G. Lanctot a dédicacé son ouvrage, peut être fier d'un tel hommage.

PAUL GaY, ptre, c.s.s.p. 